\title{
Uma polémica na história da Inquisição do século XVI: o caso João de Bolés
} A controversy in the history of the Inquisition in the sixteenth century: the case of João de Bolés

\author{
Paulo de Assunção ${ }^{1}$
}

Resumo: Jean de Cointac (conhecido como João de Bolés) teria nascido em Bolês, na diocese de Saintes, na região de Champagne, filho de uma família nobre, que cuidou dos seus estudos, tendo frequentado a Universidade de Sorbonne. Juntou-se ao grupo de franceses que invadiu o Brasil, em 1557, com o intuito de cuidar dos aspetos legais da nova colônia nas terras tropicais. Após os conflitos entre huguenotes e Villegagnon, Bolés teria deixado o forte para dar seguimento à sua trajetória pessoal. Este artigo visa abordar o caso de João de Bolés, que participou da expulsão dos franceses do litoral brasileiro e foi julgado pelo Tribunal da Inquisição em Portugal, sendo absolvido em 12 de agosto de 1564 .

Palavras-chaves: João de Bolés; protestantismo; calvinismo; França Antártica.

\begin{abstract}
Jean de Cointac (known as João de Bolés) was born in Bolés, in the diocese of Saintes, in the region of Champagne. He was the son of a noble family and studied at the University of Sorbonne. He joined the group of frenchmen who invaded Brazil in 1557 in order to take care of the legal aspects of the new colony in the tropical lands. After the conflicts between huguenots and Villegagnon, Bolés would have left the fort to follow up on his personal trajectory. This article aims to address the case of João de Bolés, who participated in the expulsion of the French from the brazilian coast and was tried by the Inquisition court in Portugal, being acquitted on August 12, 1564.
\end{abstract}

Keywords: João de Bolés; protestantismo; calvinismo; Antarctic France.

${ }^{1}$ CLEPUL, Faculdade de Letras, Universidade de Lisboa, 1600-214, Lisboa, Portugal. 
No final de 1555, os franceses se instalaram na região da baía de Guanabara, na zona adjacente à foz do rio Carioca. Villegagnon e seus companheiros tinham a intenção de estabelecer ali a Henriville. A ilha de Serigipe foi escolhida como o local para se fundar o primeiro baluarte de defesa da França Antártica. Contando com o apoio de tribos indígenas locais, a fortificação foi concluída em poucos meses e ficaria conhecida como Forte Coligny, homenagem ao ministro francês Gaspard de Châtillon (1519-1572), conhecido como Gaspar de Coligny, que preparou a expedição sigilosa de ataque às terras tropicais (Léry, 1961).

A acomodação dos invasores não foi fácil. Entre os membros que acompanhavam Villegagnon havia divergências. Em 14 de fevereiro de 1556 , ocorreu um levante que visava assassiná-lo (Lestringant, 2004). Villegagnon foi defendido pela sua guarda escocesa, mas pairava no ar uma insatisfação em relação às suas determinações. Os envolvidos no episódio tiveram punições severas. Dois deles foram enforcados, e os demais sofreram sanções leves. Apenas o líder fugiu (Fernandes, 2007).

Em 19 de novembro de 1556, três embarcações deixaram a França com destino a França Antártica. O comandante da expedição era Legendre de Boissy (?-1566), senhor Bois-le-Comte, sobrinho de Villegagnon, que conduziu os barcos com dificuldades, até aportar na baía de Guanabara, no final de fevereiro de
1557. Nessas embarcações, chegaram cinco missionários calvinistas, enviados por João Calvino, tendo como líderes os pastores Pierre Richier (1506-1580) e Guillaume Chartier (?-1560), fazendo parte deste grupo Jacques Leballeur (Ferreira, s. d.). Da expedição fazia parte também Jean de Léry (1536-1631) que, após o seu retorno à França, escrevera Histoire d'un voyage fait en la terre du Brésil, autrement dite Amérique (1578), publicado em Genebra. Nas embarcações, seguiam aproximadamente 300 protestantes (Matos, 2015).

No dia 10 de março daquele ano, era celebrado o culto calvinista e a primeira Santa Ceia ocorreria no dia 21 de março. As desavenças entre Villegagnon e Phillipe de Corguilleray intensificaram-se, na medida em que este último contestou o poder de Villegagnon e defendeu ações contra os católicos. Passado algum tempo, imaginava-se que as tensões entre católicos, calvinistas e luteranos tivessem sido amainadas. Villegagnon, em meio às disputas, passou a perseguir os huguenotes, impedindo-os de se reunirem (Léry, 1961).

Aproveitando a passagem do navio francês Les Jacques pela baía de Guanabara, alguns dos perseguidos resolveram retornar à França (Léry, 1961). Logo no início da viagem, a embarcação apresentou problemas e, diante da ameaça de um naufrágio, cinco deles resolveram regressar, a saber: Jean du Bourdel, Matthieu Verneuil, Pierre Bourdon, André Lafon e Jacques Leballeur. Villegagnon, ao saber do 
acontecido, mandou deter a todos, exigindo deles a apresentação de um texto que respondesse aos questionamentos teológicos que Villegagnon realizou. Este documento ficaria conhecido como Confissão de fé da Guanabara (1558) e foi assinado por Jean du Bourdel, Matthieu Verneuil, Pierre Bourdon e André Lafon (Matos, 2015).

A intransigência de Villegagnon foi grande quando os huguenotes foram instados a abjurar de suas convicções religiosas. Jean du Bourdel foi o primeiro a ser inquirido, sendo solicitado que argumentasse, com palavras de Santo Agostinho, as premissas que defendia. Sua resposta foi desprezada e ele foi ultrajado. Conforme destaca Dirce Lorimier Fernandes, ele se manteve «firme em suas convicções, disse que não mudaria o que escrevera e assinara até que o convencessem pela autoridade das Escrituras, que incorrera em erro» (Fernandes, 2007: 106). A sentença de Jean du Bourdel, Matthieu Verneuil e Pierre Bourdon foi a pena de morte. Os três foram estrangulados e lançados ao mar (Léry, 1961). André Lafon, que tinha o ofício de alfaiate, foi poupado, a fim de servir aos demais colonos, e Jaques Leballeur fugiu para São Vicente. ${ }^{2}$

Logo em seguida, Villegagnon escreveu a Calvino, que fora seu colega na Universidade de

\footnotetext{
2 Jacques Leballeur teria sido preso em São Vicente, em 1559. Em seguida foi levado para a Bahia e depois para o Rio de Janeiro onde foi executado em abril de 1567.
}

Paris e em Orlénas, comunicando a situação em que se encontrava (Schalkwijk, 2004). Nesse momento, teria ocorrido a saída de João de Bolés do Forte de Coligny, abrigando-se primeiramente numa aldeia na região de Olaria e, depois, seguindo para São Vicente (Salvador, 1975).

O nome de batismo de João de Bolés era Jean de Cointac, também conhecido como João Cointa. Este teria nascido em Bolês, na diocese de Saintes, na região de Champagne, filho de uma família nobre, que cuidou dos seus estudos, tendo frequentando a Universidade de Sorbonne (Abreu, 1938). Possuidor de um espírito aventureiro e extremamente comunicativo, Bolés mostrava suas posições marcadas por requintes de erudição. Ter-se-ia juntado ao grupo de franceses com o intuito de cuidar dos aspetos legais da nova colônia nas terras tropicais. Após os conflitos entre huguenotes e Villegagnon, Bolés teria deixado o forte para dar seguimento à sua trajetória pessoal. Jean de Léry questionou o comportamento de Bolés, afirmando que este:

querendo mostrar a sua ciência, começou a dar lições públicas; mas tendo principiado pelo Evangelho de S. João, matéria das mais difíceis, como bem sabem os que professam, discorria sobre seus temas sem nenhum propósito. Era, todavia, nesse país, o único sustentáculo de Villegagnon na impugnação da verdadeira doutrina. (1961: 79) 
Os embates entre católicos e calvinistas, bem como a necessidade de obter mais recursos para efetivar o domínio da região fizeram que Villegagnon retornasse à França, em 1559 (Mariz, 2008). Durante a sua ausência, ficou no comando Bois-le-Comte.

Enquanto isso, na Europa, os conflitos político-religiosos fervilhavam, em especial na França, devido à disputa pelo trono francês. Villegagnon, em Paris, revê suas posições e se torna partidário da família católica dos Guise, que demonstrava uma posição intolerante aos huguenotes (Léry, 1961). Frank Lestringant, ao considerar nesse momento a atuação dos calvinistas, afirma que:

Os pastores pareciam querer conciliar o inconciliável. Em matéria de controvérsia eucarística, seu racionalismo pode seduzir, mas sua obstinação decepciona ou revolta. Estamos prontos a lamentar o destino das vítimas, mas essas vítimas do fanatismo se mostram por sua vez mais fanáticas do que seus perseguidores. (2004: 12)

As forças portuguesas, comandadas por Mem de Sá, duelam e derrotaram os invasores. Para tanto, o governador-geral deixou a Bahia e seguiu pelo litoral para arregimentar homens (Hack, 2007). Conforme relato de Nóbrega, que o acompanhava, a chegada das embarcações ao Rio de Janeiro foi pela manhã e, de imediato, os portugueses capturaram um navio carregado de pau-brasil. Alguns homens que estavam no local fugiram, procurando abrigo na fortaleza dos franceses.

Mem de Sá, verificando que os franceses contavam com o apoio dos índios da terra, julgou melhor pedir ajuda à população de São Vicente. Contudo, alguns moradores desta vila, cientes de que o governador seguia para o Rio de Janeiro, já se encontravam no meio do caminho. Eles se reuniram e Mem de Sá determinou o ataque aos inimigos. Muitos dos que o seguiam foram de parecer contrário, dizendo que seria impossível atacar um forte tão estruturado. Apesar das divergências, Mem de Sá conseguiu convencê-los da importância de apoiar o ataque à fortaleza (Leite, 1954, I). O confronto aconteceu. Passados dois dias de enfrentamento, parte dos franceses e os índios que os apoiavam se recolheram na fortaleza, a outra parte fugiu. Entre os portugueses, havia aproximadamente uma dezena de mortos. Nóbrega descreve os franceses dizendo que estes:

seguião as heresias de Alemanha, principalmente as de Calvino que está em Genevra, segundo soube delles mesmos, e polos livros que lhe acharão muytos, e vinhao a esta terra semear estas heresias pólo gentio; e, segundo soube, tinhão mandados muitos meninos do gentio a aprendê-las ao mesmo Calvino e outras partes para depois serem mestres, e destes levou alguns o Villagalhão, que era o que fizera aquella fortaleza e se intitulara Rey do Brasil. (Leite, 1954, III: 244) 
Nóbrega informava ao cardeal-infante D. Henrique que, segundo se dizia, o rei da França, Henrique II, não queria favorecer Villegagnon, aconselhando-o a se confederar com os turcos, a fim de tomarem dos portugueses as possessões da Índia. Apesar desta trama, os portugueses conseguiram destruir parte da fortaleza dos franceses ou, como o jesuíta afirmou, «o que della se podia derubar, por não ter o Governador gente pera logo povoar e fortificar como convinha» (Leite, 1954, III: 245).

Os franceses derrotados se refugiaram entre os índios que os apoiavam e aguardaram a chegada de reforços vindos da França. A informação era a de que muitos franceses seguiriam para as terras tropicais, a fim de descobrirem os metais preciosos que houvessem na terra.

Na mesma data de 1 de junho de 1560, o irmão José de Anchieta escreveu ao padre Diego Laynes, padre-geral da Companhia de Jesus. A carta dava conta das conquistas efetivadas pelos Jesuítas e das dificuldades enfrentadas. Relatava que junto com os índios chegaram franceses que «se querían passar a nosotros, lo qual no pudieron hazer sin mucho peligro». Eles se afastaram dos companheiros que se encontravam no Rio de Janeiro, onde haviam construído casas e edificaram «una torre muy proveída de artilhería y fuerte de todas partes, onde se dezía ser mandados por el Rey de Francia a se enseñorear de aquella tierra». E complementava o Jesuíta:
Todos estos eran herejes, a los quales mandó Juan Calvino dos, a que ellos llaman ministros, para que les enseñassem lo que se avía de tener y creer. Day a poco tiempo (como es costumbre de los herejes) começaron a tener diversas opiniones unos de los otros, mas concordaron en esto que escreviessen a Calvino y a otros letrados y lo que ellos respondiessen esso ternínan todos. (Leite, 1954, III: 264)

O irmão José de Anchieta registra que um deles era João de Bolés, descrito como homem «enseñado en las artes liberales, griego y hebraico, y muy versado en la Sagrada Escriptura» (Lessa, 1934: 45)3. Ele e seus companheiros se afastaram do capitão Villegagnon, por discordarem de algumas opiniões do seu comandante, ou talvez «por querer sembrar sus errores entre los Portugueses». O Jesuíta considerava os três companheiros «idiotas», ou seja, sem grande instrução. Eram eles Pero de Vila Nova, Martim Paris e André Lafon (Abreu, 1922: 91-93). Bolés conhecia a língua espanhola e teria afirmado, desde o início, que era «hidalgo y letrado,y con esta opinión y una fácil y alegre conversatión que el tiene, hazía espantar los hombres y que lo estimassen» (Leite, 1954, III: 264-265).

Bolés escrevera uma carta ao padre Luís da Grã, que na ocasião se encontrava na aldeia de

\footnotetext{
${ }^{3}$ Vicente Themudo Lessa afirma que a referência seria a Jaques Balleur.
} 
Piratininga, dando conta de quem era e o que tinha aprendido:

después que el moderador de su adolescentia, varón singular, lo avía metido en las cuevas de las Piérides, y oviesse bebido de la fuente caballina ameníssimos arroyos de sabiduría, se avía passado ao studio de la Sacra Theología y Divina Scriptura; lo qual para más facilmente poder alcansar avía aprendido la lengua sacra esta es la hebrea, de los mesmos Rabbis, de los quales avía oydo muchos secretos, los quales platicaría con el Padre quando se viessen. Estas cosas quasi comprehendía él en su epístola, la qual concluyo con un dísticho. (Leite, 1954, III: 265)

O irmão José de Anchieta relata que não passaram muitos dias até Bolés começar a:

regoldar de sua estómago lleno el hedor de sus errores, diziendo muchas cosas de las imagines de los Sanctos que aprueva la Sancta Iglesia, del Sacratíssimo Cuerpo de Christo, del Romano Pontífice, de las indulgentias y outras muchas cosas, las quales él adobava con un cierto sal de gratias, de manera que al paladar de pueblo ignorante no solamente no parecían amargas, mas aún muy dulces. (Leite, 1954, III: 265)

Tomando conhecimento dos efeitos que o discurso de João de Bolés surtia no seio da população vicentina, o padre Luís Grã deixou a aldeia de Piratininga e seguiu para o litoral. Seu intuito era «se opponer a la pestilência, y arrancar las raízes aún tiernas deste mal que começava a brotar». Bolés teria enviado uma declaração ao padre Luís da Grã, acusando-o e repreendendo-o «muy agramente porque no partia el pan dela doctrina a los Portugueses por trabajar en la conversión de los infieles». Outras afirmativas do mesmo teor foram feitas por Bolés. Tal situação induziu o padre Luís da Grã a procurar o vigário Gonçalo Monteiro e lhe propor que impedisse Bolés de ir adiante com «esta peçonha luterana» (Bicalho, 2008: 41.) E também que este vigário, nos sermões públicos, admoestasse o povo a que se «guardasse destos hombres y de los livros, que truxeron, que eran llenos de herejías». Apesar de tal determinação, o irmão José de Anchieta registra que os menos instruídos frequentemente louvavam o francês, e se «maravillávanse de su sabiduría y eloquentia, y predicavan el conoscimiento que tenía de las artes liberales». Estas pessoas também passaram a caluniar o padre Luís da Grã, afirmando que ele havia urdido infâmias sobre Bolés e que se encarregariam de persegui-lo. E o irmão José de Anchieta lamentava: «Yvase ya la pestilentia poco a poco encaxando en los coraçones incautos de la imperita multitud, que no ay Duda sino que se ovieran de inficionar muchos con esta ponçonha mortal si no oviera quien le resistiera» (Leite, 1954, III: 266). Realmente, a autoridade do padre Luís da Grã havia diminuído no seio da comunidade.

O irmão José de Anchieta informa que João de Bolés foi enviado à Bahia, onde seria mais bem informado sobre a causa posta contra 
ele. Dizia o Jesuíta que o que «allá y aca se hizo acerca dél, porque por cartas particulares se sabra y no es cosa que convenga para carta general, lo callaré» (Leite, 1954, III: 266-267). Conforme destaca o padre Serafim Leite, a primeira devassa feita contra Bolés teria sido «escondida». A questão parece controversa, pois consta que, no 14 de maio desse mesmo ano, Gonçalo Monteiro o teria absolvido (Annais..., 1904: 235). É possível inferir que o irmão José de Anchieta não concordava com tal procedimento. Por prudência, não tecia maiores comentários.

A fortaleza dos franceses era muito resistente; localizada no alto de uma colina, só era acessível por meio de um caminho estreito e de difícil acesso, em meio às rochas, segundo o irmão José de Anchieta. Os invasores tinham grossa artilharia e contavam com grande quantidade de alimentos estocados. Entre os portugueses, muitos achavam que o forte era inexpugnável. A peleja foi cruel. Ambas as partes tiveram muitas baixas. Os que lutavam com Mem de Sá já haviam perdido a esperança de vitória, quando os franceses começaram a abandonar o forte e a seguir para as terras dos índios que os apoiavam.

No final, os portugueses tomaram a fortaleza repleta de armamentos e gêneros alimentícios. $O$ irmão José de Anchieta, atento às coisas da fé católica, destaca que «max Crux o alguna imagen de Sancto o señal alguna de cathólica doctrina no se halló - grande muchedumbre de livros heréticos, entre los quales (si por verntura esto es señal de su recta fe) se halló un missal con las imagines Raídas» (Leite, 1954, III: 268).

A questão acerca de João de Bolés ocupou as atenções do padre Luís da Grã. Em 22 de abril de 1560, o religioso redigiu uma petição contendo depoimentos de vários padres da Companhia de Jesus contra o fugitivo João de Bolés. O objetivo do documento era atalhar a atuação do herege que, perseguido no Rio de Janeiro, buscou refúgio na região de São Vicente. Num primeiro momento, os portugueses ali estabelecidos aprovaram a presença de João de Bolés, considerando as importantes informações sobre os franceses que ocupavam o Forte Coligny, em especial sobre as disputas religiosas entre eles. Passado algum tempo, ela foi considerada inconveniente devido à acirrada defesa das ideias protestantes, perturbando a comunidade católica (Fernandes, 2007).

A petição foi determinada por Gonçalo Monteiro, vigário e ouvidor eclesiástico das capitanias de Santos e de Santo Amaro, e pelo bispo da cidade de Salvador da Bahia, conforme solicitação do padre Luís da Grã (Leite, 1954, III). As testemunhas ouvidas foram Fernão Luís, o irmão José de Anchieta, Pero de la Cruz, Jorge Moreira, Eliodoro Ebanos, Josepe Adorno, padre Manoel da Nóbrega, Antonio Teixeira, Cristóvão Dinis e Jorge Grego e Tavares. 
O texto mencionava que o padre Luís da Grã, no ano anterior (1559), havia feito uma devassa sobre os «errores, heresias e novidades que se começavam a semear pela terra» que eram seguidos pelos franceses que invadiram o Rio de Janeiro. As informações foram encaminhadas para o bispo. Após a primeira devassa, surgiram novas denúncias, confirmando o «prejuizo da nossa santa fee catolyca», afirmava o padre Luís da Grã. Por este motivo, foi redigido um novo requerimento para inquirir as testemunhas (Leite, 1954, III: 178).

Pero de la Cruz, vivendo na região da Borda do Campo, no planalto de Piratininga, dizia ter ouvido de João de Bolés «muitas cousas escandalosas». Na casa dos Jesuítas situada na aldeia de Piratininga, Pero de la Cruz teria confirmado ao padre Luís da Grã o teor das heresias. João de Bolés lhe teria dito que: «A Igreja de Roma não tinha mais que ha de Lisboa ou de Paris, que tamta denidade tem um Bispo como ho Papa, e ho Papa hé hum homem como nós, hum bugiarão, que tem em Roma putaria de homens, por que pagam dinheiros». Prosseguindo, Bolés teria dito que:

Nosso Senhor mandou a São Pedro que pregasse aos judeus e São Paulo aos gentios, e que São Pedro não havia de sair do mandado de Deus pera deixar de pregar aos judeus, e ser Papa, negamdo ho que dele se diz que foi vinte e quatro anos Papa; que as bulas do Papa hé huma falsydade mui grande, que as faz por tirar dinheiros e por dois reales absolve de culpa e pena; e que não há-de crer outra cousa senão ho que está na Sagrada Escritura, e que disse São Paulo que aimda que viese algum amjo do seo a pregar fora do que eles pregavão, que não no cresem; [...]. (Leite, 1954, III: 179)

Estas particularidades defendidas pelos protestantes, especialmente pelos calvinistas, causavam espanto aos católicos, que não atinavam com as implicações de tais afirmativas. Pero de la Cruz acrescentava ainda que Bolés havia desdenhado uma excomunhão feita pelo vigário Gonçalo Monteiro. Tais declarações foram feitas «muito em segredo e em lugares apartados». Bolés tomara a precaução de avisar a Pero de la Cruz que «as não disese a ningem até ele não ser hido desta terra». Interpelado por Luís da Grã, Pero de la Cruz confirmava que tais opiniões eram do próprio Bolés e de mais ninguém. Estas informações foram testemunhadas pelo irmão José de Anchieta e pelo padre Fernão Luís, que acompanhavam o padre Luís da Grã na vila de Santos, naquela circunstância (Leite, 1954, III: 180).

Tempos depois, o padre Luís da Grã, encontrando João de Bolés em Santos, indagou-o sobre a veracidade de suas denúncias, e este respondeu que dissera 0 «que the dezião os luteranos». Outro denunciante, Eliodoro Ebanos, no seu depoimento, afirmava ter ouvido de Bolés «certas cousas escandalosas e ereticas». O padre Manoel da Nóbrega, por sua vez, também dissera ao padre Luís da Grã que 
havia «ouvido cousas por onde ho tinha por muito sospeito» (Leite, 1954, III: 181).

Na citada petição, o padre Luís da Grã afirmou que, na Páscoa daquele ano,João de Bolés o procurou para se desculpar de algumas coisas que diziam a seu respeito, tendo mencionado que:

no Rio de Janeiro herao tres seitas de que ele hera cabeça de huma, e da outra Monsior de Villaganhão, e da outra herao dous menistros que mandara Joam Calvino, de Janevra, e que todos tres se chamao huns aos outros ereges, por algumas diferenças que antre eles avião nas opiniões; e perguntando-lhe por elas, confesava aver consentido na comunhão sub utraque specie; e que não se consertando eles, escreverão todos ao almirante (Gaspar de Coligny) e aleterados de França e Janevra pera que the mandasem a resolução, a qual não hera chegada até o tempo que deles se apartara. (Leite, 1954, III: 181-182)

O padre Luís da Grã enfatiza que Bolés se gabava de que, na ceia celebrada entre os franceses, as práticas religiosas foram oficiadas por pessoas que não tinham sido ordenadas, fato que também chegou ao conhecimento do padre Manoel da Nóbrega.

Em outra ocasião, Bolés dissera, perante Jorge Grego e outro homem chamado Tavares, que os gregos celebravam os cultos sem louvor às imagens dos santos. Além disso, referiu com desprezo as Cruzadas realizadas pelos católicos.
Estes argumentos justificavam a decisão do padre Luís da Grã quanto a deter Bolés na Bahia, antes que ele partisse para o reino. E que se tomassem as diligências que o fato exigia, incluindo os companheiros de Bolés, em virtude de suas idênticas ideias protestantes, sendo as culpas enviadas ao bispo na Bahia.

$\mathrm{Na}$ etapa seguinte, foram ouvidas as testemunhas, visando à averiguação do comportamento de João de Bolés.

O padre Manoel da Nóbrega registrou que, estando na cidade de Salvador, na pousada onde vivia Bolés, ouviu-o «dizer muito mal do Papa Clemente Septimo, referindo trovas e versos que the fizeram». Em outra ocasião, o Jesuíta leu uma crônica que louvava o pontificado deste Papa e a forma como procedeu contra Martinho Lutero. Após a leitura, Nóbrega notou «má vontade» de Bolés (Leite, 1954, III: 184).

Outro fato grave, relatado por Nóbrega, era Bolés possuir «hum seu cartapasio», do qual lera alguns trechos transcritos de um livro de Martinho Lutero. Indagado pelo religioso se não tinha medo de receber a excomunhão, uma vez que era proibida a leitura de tal livro, Bolés respondeu sem receio que «na sua terra hera licito ler todos os livros». Em outro momento, quando eram condenadas as práticas luteranas, Bolés «sempre escuzava e desculpava e louvava os ireges de retos e ables e de boons leterados; e, na maneira de referir as erezias, parecia querê-las persuadir». Quando 
indagado sobre a situação de Lutero, que se casara, mesmo sendo frade de Santo Agostinho, sua resposta foi no sentido de defender o monge agostiniano, desculpando-o de tal comportamento, ao mesmo tempo que louvava suas virtudes (Leite, 1954, III: 184).

Numa outra ocasião, quando os temas eram o sacramento da unção e o teor da Epístola de São Tiago, ${ }^{4}$ o padre Manoel da Nóbrega registra que Bolés defendera as ponderações de João Calvino. A externalização da concordância com os preceitos calvinistas também se deu em outra situação, estando presente o governador Mem de Sá e outras pessoas. Prontamente, o governador e os Jesuítas o repreenderam por defender ideias tidas como heresias.

Bolés não adorava ao Santo Sacramento e, pela afrontosa evidência, foi repreendido pelo colono Gaspar Barbosa. Em resposta, ele teria dito: «que Deus sabia seu coração». Bolés, de espírito irrequieto e crítico, ao seguir numa embarcação em que ia o governador, observou que na oração «Pater noster», proferida a bordo,

faltavão sertas palavras que estavam no grego; elle com elas ho rezava, as quais palavras ele testemunha achara depois que estavam em huns livros da doctrina luterana, que agora vierão do Rio de Janeiro com outros muitos também luteranos. (Leite, 1954, III: 186)
Outro impropério proferido por Bolés, segundo o padre Manoel da Nóbrega, foi a afirmação de que o «Livro dos Macabeus não hera autentico». Além disso, teria dito «muitos herrores» sobre a predestinação; contudo, o Jesuíta não se lembrava dos detalhes (Leite, 1954, III: 186-187).

Concluído o testemunho do padre Manoel da Nóbrega, seguiu-se o do irmão José de Anchieta. Sob juramento, ele confirmou as declarações de Pero de la Cruz que, em diferentes circunstâncias, denunciara as ideias de Bolés e a recomendação para que o denunciante tivesse «muito grande segredo» sobre o assunto (Leite, 1954, III: 188). Passados alguns dias, na casa de Gonçalo Monteiro, foram ouvidas outras testemunhas que deram juramento.

O padre Fernão Luís Carapeto, também Jesuíta, revelou que ouvira de Pero de la Cruz o que João de Bolés lhe dissera sobre a Igreja de Roma: «não tem mais denidade que outra qualquer, e que tanta denidade tinha Bispo como hum Papa, e que ho Papa hera hum homem como os outros e bogiarão». Além disso,

- as bulas do Papa hera uma falsidade mui grande e que ho fazia por tirar dinheiros;

- as excomunhões do Vigario daqui de Santos que tanto valyão como nada;

- não avia mais santos que os apóstolos, e que os outros se não podiam chamar santos; e que nem avia ha hi Purgatorio, que loguo hião ao imferno ou parayzo como de quá deste mundo

${ }^{4}$ Iac. 5, 14. 
partião, que bastava a Paixão de Christo pera se salvarem. (Leite, 1954, III: 189)

Pero de la Cruz finalizou a denúncia afirmando que the fora recomendado segredo sobre o assunto.

Em 20 de janeiro de 1561, o padre Luís da Grã foi ouvido, agora como testemunha, na aldeia de São Paulo. Ele ouviu a leitura de sua petição e os depoimentos descritos nos parágrafos acima. Indagado sobre o assunto, o religioso confirmou o conteúdo de sua petição (Leite, 1954, III).

No último dia de janeiro daquele ano, novas testemunhas foram ouvidas. O padre Adão Gonsalves, Jesuíta que esteve na capitania de Porto Seguro e participou da tomada do Forte Coligny, testemunhou que «ouvio ele testemunha humas porfias grandes que tinhão sertos homens com ho dito Monsior Bolés». Estes homens the revelaram que Bolés afirmava que «a santidade não estava nas igrejas, nem nas cruzes, nem nas contas, e outras palavras que davao escamdalo às pessoas que as ouvião». Além disso, Bolés considerava os franceses «mais santos que os Padres de Jesus» (Leite, 1954, III: 191-192).

Adão Gonsalves, durante a sua estada em Porto Seguro, encontrou-se com Bolés na casa de Felipe Gilhem, provedor da fazenda. Estavam presentes ainda Diogo Alvares e Gaspar Barbosa, moradores naquela localidade (Abreu, 1938). Nessa reunião, Bolés teria defendido as ideias dos luteranos, considerando-as muito boas, e os elogiou por serem «boons leterados». Adão Gonsalves confirmou que «loguo, sem ho aver nunqua visto nem conhecido nem saber dele nada, teve muito roim sospeita dele e lhe parecerão muito mal suas cousas» (Leite, 1954, III: 192).

No final da petição, o padre Luís da Grã ressalta que dissera ao povo de São Vicente que «se gardasem dos Franceses que amtam herao chegados do Ryo de Janeiro, honde vivião lluteramente, como elles mesmos o pregavao e se vya pelos llyvros que traziao, e que os que vyerão da Carioca erão todos huns». Este aconselhamento se referia a João de Bolés e seus companheiros (Leite, 1954, III: 195).

O processo, que começara na capitania de São Vicente, seguiu para a Bahia e posteriormente para Lisboa.

O padre Manoel da Nóbrega, em 12 de junho de 1561, escreveu ao padre Diego Laynes. Na missiva, fazia um breve balanço da sua atuação nas terras tropicais, dos avanços e impasses da Companhia de Jesus. Destacava que era necessário abrigar e educar os filhos dos índios, e ministrar-lhes o conhecimento básico, acrescido do latim. Pouco a pouco, eles estariam formados, sendo depois enviados a Portugal, onde aprenderiam letras e virtudes, para retornarem posteriormente como «homens de confiança». Nóbrega julgava que tal iniciativa era plausível, uma vez que «si unos 
herejes franceses que poblavan cierta tierra deste Brasil usavan desto, y embiavan muchos niños a Calvino y a outras partes para que enseñados en sus errores volbiessen a la tierra, quanto más razón será hazer nosotros lo mismo?» (Leite, 1954, III: 363). A conversão dos indígenas ainda renderia grandes debates, mas, naquele momento, Nóbrega reconhecia que a estratégia dos franceses poderia ser adotada em pouco tempo.

No final de 1560, João de Bolés seguiu de São Vicente para a Bahia e, logo ao desembarcar, o bispo D. Pero de Leitão (1519-1573) determinou a sua prisão, que foi conduzida pelo meirinho Manoel Gonçalves. Em seguida, o prisioneiro tomou consciência das acusações que the eram imputadas.

Em sua defesa, em 26 de agosto de 1561, Bolés teria escrito uma carta ao bispo, explicando suas posições. 0 processo manteve-se na Bahia até ao dia 9 de janeiro de 1563, quando o cardeal D. Henrique determinou que a documentação fosse remetida à Inquisição de Lisboa (Leite, 1954, III: 195).

Neste ínterim, na Bahia, em 26 de junho de 1562, o padre Leonardo do Vale escreveu aos membros da Companhia de Jesus que viviam no colégio de São Roque, em Lisboa. Relatava que os franceses continuavam visitando a costa brasileira, tendo tomado uma nau procedente da cidade do Porto. Soubera que havia aproximadamente sete naus francesas ancoradas na região da baía de Guanabara. Os franceses haviam atacado a vila da capitania do Espírito Santo, pela sua vulnerabilidade. Por sorte, uma embarcação portuguesa que seguia de São Vicente para o reino chegou naquele momento, derrotando os franceses, que tentaram fugir levando um carregamento de pau-brasil. Contudo, alguns deles foram detidos e feitos prisioneiros. Esse episódio destaca o sofrimento e as dificuldades dos religiosos que ali viviam. Leonardo do Vale revela o temor aos franceses «como homens cobiçosos de fazendas alheas, e agora como herejes». Se os franceses fossem bem-sucedidos nos seus objetivos, como temiam os religiosos, «averia de muitos serem contaminados como são os de pequena idade, criando-sse com elles, e outros, que por medo do mao tratamento que dão aos fieis, podião correr o mesmo perigo» (Leite, 1954, III: 497).

Leonardo do Vale relatava que, havia pouco tempo, um barco que seguia para Pernambuco com Jesuítas a bordo se desgarrou e foi parar na Paraíba, onde havia franceses. Eles não fizeram nenhuma maldade contra os cativos, dizendo que os mandariam de volta, quando tivessem tempo. A promessa se cumpriu, mas os franceses «tomavao por passatempo escarnecer e zombar dos livros de rezar, que levavão, e imagens, dizendo, deos de pão, deos de frandes, deos de caxa, e chamando-lhes de papistas, e outras cousas em que the parecia favorecerem sua cegeira». João de Bolés, continua Leonardo do Vale, estava preso há mais de um ano em uma cadeia que se asseme- 
Lhava a uma verdadeira masmorra. Leonardo do Vale o descreve como «pertinaz como se outro letrado não ouvera no mundo». Mesmo preso ele não deixava de falar:

o que the vem à vontade, e He ele tam gabado de sutil e delicado engenho que se nosso Senhor por sua bondade não ajudase nesta parte tanto ha Nação Portuguesa, como sempre ajudou, não poderia deixar de se apegar algum aos que ally vão. (Leite, 1954, III: 498)

Durante a estada de João de Bolés na Bahia, dois moradores antigos e casados foram atraídos por suas ideias consideradas heresias. Ambos foram punidos. Um recebeu penitência solene na Sé, e o outro foi obrigado a usar um sambenito para sempre, além de ser proibido de sair fora dos muros e ter que visitar o colégio dos Jesuítas duas vezes ao dia. Leonardo do Vale menciona que Bolés não foi queimado, porque seria remetido para Portugal.

A petição do padre Luís da Grã foi enviada pelo padre provincial, por intermédio do padre Rodrigo de Freitas, ao inquiridor, no colégio da Bahia, em 24 de março de 1563. João de Bolés, ao tomar conhecimento de que fora instaurada uma inquirição contra ele, passou a agir com mais prudência. Na sua defesa, Bolés argumenta que simplesmente divulgava ideias calvinistas, mas se mantinha católico.

Concluída a devassa em terras tropicais, o preso João de Bolés foi entregue ao mestre da nau Barrileira para seguir a Portugal no dia 8 de maio. Passados cinco meses, em 28 de outubro de 1563, Bolés entrou no cárcere da Inquisição de Lisboa (Leite, 1954, III).

O réu compareceu a diversas audiências perante o Tribunal do Santo Ofício de Lisboa. A primeira sessão ocorreu em 5 de novembro de 1563, quando negou que tivesse acreditado em outra fé, senão a fé católica. Nas demais inquirições, Bolés continuou a negar as acusações, apesar de ser admoestado. Demoraria alguns meses para que Bolés confessasse suas culpas e pedisse o perdão, a fim de conquistar a liberdade. Consta que ele teria lido um livro luterano intitulado Dois mártires que se perseguiram e houveram mau fim. Também é mencionado que escrevera um livro contra judeus e mouros, Colóquio de Joavana senhor de Boulez contra Alchana de Farao, e um livro cujo teor seria contra Calvino, refutando algumas de suas teses.

Enquanto o processo tramitava no Santo Ofício, os calvinistas tiveram a perda do seu líder, João Calvino, que faleceu em Genebra, no dia 27 de maio de 1564. Havia alguns anos que Calvino sofria com uma hemorragia pulmonar, gota e pedras nos rins, sendo constantemente acusado por seus opositores (Costa, 2009).

Em 12 de agosto de 1564, conforme os processos n. ${ }^{\text {ss }} 5451$ e 1586 do Tribunal do Santo Ofício, a Inquisição absolveu João de Bolés. A sentença menciona que ele fora luterano 
e que confessara arrependimento, fazendo abjuração em forma e recebendo também penitências espirituais. Os juízes julgaram por bem ser recebido novamente na comunhão católica (Annais..., 1904: 268-270). A pena foi o encarceramento num convento, com a obrigatoriedade de rezar sete salmos penitenciais às quartas e sextas-feiras e confessar-se regularmente, ficando impedido de se comunicar com pessoas suspeitas e de sair de Portugal sem autorização dos inquisidores. Em parte, a decisão favorável deveu-se à sua atuação no Brasil, tendo em conta que ele revelara os planos dos franceses aos portugueses, tendo participado na tomada do Forte Coligny. Era destacado no processo que os depoimentos de Mem de Sá e António de Castro comprovavam os préstimos de João de Bolés.

No dia 22 de agosto, Bolés deu entrada no Convento de São Domingos, em Lisboa, passando a frequentar os sacramentos. Em 15 de novembro do mesmo ano, ele foi liberado, passando de Portugal para a Índia (Leite, 1954, III).

Antes de seguir para o Oriente, João de Bolés escreveu o texto Paradoxo ou sentença, philosophica contra opinião do vulgo que a natureza nam faz o homem senam a industria. Este texto, dirigido ao rei D. Sebastião, foi impresso em Lisboa por Marcos Borges. A data da primeira edição é desconhecida, e a segunda edição é do ano de 1566 (Ribeiro, 1968). No mesmo ano e pela mesma casa de impressão, João de Bolés publicou Catholica e religiosa amoes- tação á asubjetar, o homem seu entendimento a obediência da fé com breve \& crara exposição do simbolo dos apostolos, pelo senhor des Bolez. 0 texto foi dirigido à Sereníssima D. Maria, princesa de Parma e Valencia, regente de Flandres.

Em 1569, em Goa, ele teria sido acusado de culpas de luteranismo, sendo preso e entregue à justiça secular. Julgado e condenado, foi executado na fogueira em janeiro de 1572 (Annais..., 1904). Conforme destaca Dirce L. Fernandes, Bolés «foi, na verdade, apenas mais uma vítima de um contexto em que era proibido discordar da fé católica» (Fernandes, 2007: 110).

\section{Bibliografia}

\section{Impressa}

Abreu, C. (1922). Primeira visitação do Santo Ofício às partes do Brasil pelo licenciado Heitor Furtado de Mendonça - Confissões da Bahia 1591-1592. s. n. São Paulo;

Abreu, C. (1938). João Cointa, senhor de Bolés. Em: C. Abreu. Ensaios e estudos. 3. a série, Sociedade Capistrano de Abreu/Livraria Briguiet. Rio de Janeiro;

Annais da Biblioteca Nacional do Rio de Janeiro (1994). Biblioteca Nacional do Rio de Janeiro. Rio de Janeiro. Vol. 25;

Costa, H.M.P. (2009). João Calvino - 500 anos. Editora Cristã. São Paulo;

Eriksson, J. (2009). Travelling savage spaces: Jean de Léry and territorializations of «Ana tarctic France» Brazil 1555-1560. Em: K.G. Hammarlund (ed.). Borders as Experience. University of Gothenburg. Halmstad;

Fernandes, D.L. (2007). Heresias e repressão: A visitação do Santo Ofício durante a união ibérica. Em: D.L. Fernandes, P. Assunção, A.J. Gaz, 
I. Barroso, V. Gianastácio e M.A.M. Ramos. Religiões e religiosidades: Leituras e abordagens. Arké. São Paulo;

Ferreira, F. (s. d.). A presença dos reformados franceses no Brasil colonial. Em: F. Ferreira (org.). A glória da graça de Deus: Ensaios em honra a J. Richard Denham Jr. Fiel. São José dos Campos;

Gaffarel, P. (1878). Histoire du Brésil français au siezieme siècle. Maisonneuve. Paris;

Gillies, J. (1979). Los martires de Guanabara. Tarassa. Barcelona;

Hack, O.H. (2007). Sementes do calvinismo no Brasil colonial. Cultura Cristã. São Paulo;

Leite, S. (1938-1949). História da Companhia de Jesus no Brasil. Portugália/Instituto Nacional do Livro. Lisboa-Rio de Janeiro. Vols. 1 e 2;

Leite, S. (1954). Cartas dos primeiros Jesuítas do Brasil. 3 vols. Comissão do IV Centenário da Cidade de São Paulo. São Paulo;

Léry, J. (1961). Viagem à terra do Brasil. Biblioteca do Exército. Rio de Janeiro;

Lessa, V.T. (1934). Anchieta e o supplicio de Bauller. Record. São Paulo;

Lestringant, F. (2004). Le huguenot et le sauvage. Droz. Genebra;

Matos, D.O. (2015). A confissão de Guanabara: Visões sobre os missionários da França Antártica. Acta Científica - Ciências Humanas. 1 (8);

Ribeiro, L. (1968). Um aventureiro erudito João Cointhor de Boules. STVDIA. 23: 228-274;

Salvador, F.V.(1975). História do Brasil 1500-1627. (6. ${ }^{a}$ ed.). Melhoramento. São Paulo;

Schalkwijk, F.L. (2004). O Brasil na correspondência de Calvino. Fides Reformata IX.1:101-128;

\section{Digital}

Bicalho,M.F.(2008). A França Antártica, o corso, a conquista e a "peçonha luterana" [Versão eletrónica]. História, 27: 29-50. Acedido em 21 de novembro de 2018, em: http://www.scielo.br/ pdf/his/v27n1/a04v27n1.pdf;

Mariz, V. (2008). Villegagnon: Herói ou vilão? [Versão eletrónica]. História, 27: 51-75. Acedido em 21 de novembro de 2018, em: http://www. scielo.br/pdf/his/v27n1/a05v27n1.pdf. 